V.I. TIKHONOV, dr. of techn. sciences, professor, "ONAT", Odessa,

A. TAHER, PhD student, "ONAT", Odessa,

O.V. TYKHONOVA, teacher, "ONAT", Odessa

\title{
CONVEYOR MODULE RESOURCE SCHEDULING IN PACKET BASED COMMUNICATION CHANNEL
}

The paper focuses researches on channel resource reservation and scheduling in packet based networks. An axiomatic basis for enhanced packet based internetworking design formulated. A cross-layer method originated to leverage integrated heterogeneous data flow in converged digital channel based on cyclic conveyor module resource scheduling. Figs.: 2. Refs.: 22 titles.

Keywords: packet based network, conveyor module resource scheduling, cyclic conveyor module.

The problem statement. Migration towards next generation networks faces challenges of QoS policing for real time applications and machine-tomachine interaction. The legacy per-flow based QoS provision for IntServ model was standardized in resource reservation protocol (RSVP) which proved overly complicated, purely scalable and therefore, not widely used. An RSVP successor was presented in 2010 as next step in signaling (NSIS) protocol suite to provide extended functionality for both IntServ and DifServ routers. Another modern trend in telecoms is software-defined networking (SDN) intended to consolidate the control plane of network resource management; it has been experienced in some plain architecture applications, e.g. big data centers. This approach encounters management complexity, feedback time delays and system robustness issues. Eventually, neither IPbased resource reservation methods nor SDN decisions demonstrate promising achievements in reliable wide are end-to-end packet based voice communication over the Internet.

Last years, the "All over IP" service delivery has being developed in $4 \mathrm{G}$ mobile networks based on voice over LTE (VoLTE); yet, it is not fully equivalent to VoIP technique as it solely supports virtual end-to-end voice connections in an autonomous administration system (AS) for dedicated transporting infrastructure. One of the first climes for VoLTE mobile network integration was announced in 2015 by two leading American operators Verizon and AT\&T; but it turned to be difficult task, and therefore, not accomplished yet.

Consider the telecom/Internet service integration during last few decades we state that circuit-to-packet network convergence remains an actual problem. In particular, enhanced uniformed algorithms of multimedia data

(C) V.I. Tikhonov, A Taher, O.V. Tykhonova, 2016 
scheduling in packet based digital channel are to be investigated.

Related publication analysis. The multimedia QoS aware data management is one of the principal issues of NGN concept for network convergence and service integration. An exhaustive survey on telecommunication service evolution given in [1]. The circuit-switched communications designed in 80-th years of 19-th century, and packet-switched computer networks emerged 100 years later on, have been traditionally occupying different niches within corporations. Because of poor voice-over-IP quality and call latency, hybrid systems expected in the near future [2]. As noted in [3], the overall network and media convergence will be the buzzword for the first decades of this century.

The use of multiple communication modes in a single network offers convenience and flexibility but faces new problems; among those, the sheer demand for bandwidth is perhaps the most significant [4]. Another key issue is the need for standards that ensure seamless operation with multiple enduser platforms; this is not only a technical problem, but also involves relationship among multiple entities [5]. The specialist of the Allstream Inc. outline five networking stages evolution to next generation IP managed network [6]; despite an amount of work underway, there is a still not complete agreement on a specific definition of "NGNs" [7]. Herewith, next generation core networks migrate to managed IP networks apart from PSTN and common Internet with respect to wholesale payment, peering policy, routing methods and interworking protocols. They say in [7] that packets do not require end-to-end dedicated path while interworking between the NGN and existing networks provided through media gateways. This poses significant research challenges in timely service delivery, efficient spectrum utilization, protocol stack unification, vertical protocol integration mechanisms in heterogeneous networks and QoS negotiation during inter-system handoff and diverse network interconnection [7].

Experts in [8] indicate that telecom network interoperability (NI) is one of most critical issues in communications to solve in the 21-st century because it is the main enabler for service convergence. Actually, there is no unique definition of the "interoperability" term, which depends on vendor implementation and abstraction levels. The IEEE formulates the NI function in terms of customer view [9]. Quoting the [8], the system view on the interoperability foremost involves specification of protocol suites along with the end-to-end connection and QoS control. Service providers, such as Verizon and AT\&T in the recent past, have been obliged to operate distinct networks for IP and transport [10]. As IP transport systems lack dynamic interaction, IP networks underuse transport potentials being far from benefits of dynamic circuit switching (more scalability, higher data rates and lower 
power consume); in fact, statistical multiplexing is less critical in core transport with high aggregated and relatively smooth data flows [10].

To compromise packet and circuit switching techniques across an autonomously software driven network (SDN), an open flow protocol and related unified architecture have been originated in [10]. This framework implies that all the underlying switching hardware (packet and circuit switches) will be driven by an external control plane including network operating system with on top applications and open flow protocol to manage data flow tables of switches.

A comprehensive study of modern data transmission methods given in [11]. In particular, bandwidth allocation and resource scheduling issues considered, such as time division switching fabric based on a slotted random access bus. The aforesaid method corresponds to the hybrid packet/time slotted circuit switched scheme (HPTS) presented in [12] where real time data segments follow a circuit path with no packet loss or jitter; instead, the other ones are following packet switched path being statistically multiplexed.

The problems of telecom and Internet technologies convergence in the context of multimedia data management reflected in [1,13]. The issues of machine type communication (MTC) standardization highlighted along with open network virtualization aspects. The MTC systems give rise to new demands of communication scalability due to the rapidly increasing network device variety and data transmission requirements diversity. Industrial MTC applications for remote wireless control of heavy machinery in remote or hazardous places may need to provide extremely fast and reliable interconnectivity unforeseen in $4 \mathrm{G}$ standards and related technologies. Therefore, the $5 \mathrm{G}$ specifications are in demand to commit the relevant functionality for these applications. [13].

Amongst diverse convergence mechanisms, the Ethernet is appealing technology becoming de facto vehicle for Internet transport deployment at the access, aggregation, and even core levels [14]. The key benefits of that are ubiquity, simplicity and scalability for integration across different system hierarchy. Recently, virtual private LAN services (VPLS) appeared in metro Ethernet services by the advent of conventional MPLS; this requires a new inter-domain technique.

The autonomous network's interoperability concerns largely related to mobile transport evolution. According to [14], one of the biggest cost challenge facing mobile service providers today is the backhaul transport. However, existing industry solutions, tailored for circuit-switch paradigm of hub-and-spoke connectivity between cell sites and centrally located radio controllers, are not conducive to meet fixed/mobile convergence. Eventually, the seamless interworking between the mobile packet core and backhaul transport infrastructure remains to be a great challenge for next few decades. 
Objectives. Summarizing the cited publications we note that circuitswitched systems (largely associated with telephony) and modern Internet, still occupy different niches in telecom market as poor VoIP quality and call latency hamper the "all over IP" progress. This poses research challenges in protocol stack unification and network interoperability as IP is not sufficient protocol for network integration on the core and aggregation levels for real time applications. In particular, bandwidth allocation and resource scheduling are to become modern key business drivers.

The goal of this work is development a uniformed method of hybrid packet/circuit switched resource scheduling for QoS-aware multiservice network interaction in converged system architecture.

Advanced internetworking design. The modern Internet is based on the TCP/IP four-layer model wherein IPv4 or IPv6 is the key internetworking protocol. It means that, regardless of internal framework, any autonomous system (AS) must be compatible with a partner network facilitating IP transactions. This resulted in stochastic time delays and packet loss which hinder the QoS provision. To overcome this problem we introduce a QoSaware packet based internetworking method with a mechanism of packet delivery latency control.

Take an arbitrary AS with four ports $P_{1}-P_{4}$ connected in physical ring topology, fig.1, $a$. Assume ports $P_{1}-P_{4}$ form backhaul AS infrastructure. Define internal AS "zero-port" P0 connected with $P_{1}-P_{4}$. Map the ring backhaul in a virtual mesh topology backhaul, fig.1, $b$. The open network graph in fig.1, $b$ is built by means of three types of virtual links:

a) Directed open physical links divided in duplex virtual channels with asymmetric simplex capacities $\left(C_{1}^{\text {In }}, C_{1}^{\text {Out }}\right) \div\left(C_{4}^{I n}, C_{4}^{\text {Out }}\right)$; these links determine the maximal possible peak value of input/output traffic intensity between the autonomous system and its open environment individually for any AS port;

b) Directed virtual links between any pair of border gateway ports $P_{1}-P_{4}$ with asymmetric simplex capacities $\left(C_{k m}, C_{m k}\right), k, m=1,2,3,4$; these links determine the maximal possible peak value of direct/reverse transit traffic intensity between any two ports $P_{k}, P_{m}$;

c) Directed virtual links between any border gateway port $P_{1}-P_{4}$ and internal part of AS (port $P_{0}$ ) with asymmetric simplex capacities $\left.C_{k 0}, C_{0 k}\right), k=1,2,3,4$; these links determine the maximal possible peak value of input/output traffic intensity between the internal part of AS and open environment individually for any AS port. 
Fig. 1, $c$ presents aforesaid open network graph in matrix form, wherein $C_{0}^{I n}$ is current virtual channel capacity for the traffic generated by external environment towards internal part of AS (e.g. targeting port $P_{0}$ ); $C_{0}^{O u t}$ is current virtual channel capacity for the traffic generated by internal part of AS (port $P_{0}$ ) towards external environment of AS:

$$
C_{0}^{I n}=\sum_{k=1}^{4} C_{k 0}, \quad C_{0}^{\text {Out }}=\sum_{k=1}^{4} C_{0 k} .
$$

Based on the matrix graph in fig. $1, c$ we define the scalar and vector network metrics divergence $\left(D_{\text {local }}^{\text {Scalar }}, D_{\text {local }}^{\text {Vector }}\right)$ for AS-local traffic throughput:

$$
\begin{gathered}
D_{\text {Local }}^{\text {Scalar }}=C_{0}^{\text {Out }}-\mathrm{C}_{0}^{\mathrm{In}}, \\
D_{\text {Local }}^{\text {Vector }}=\left(C_{0 k}-\mathrm{C}_{\mathrm{k} 0}\right), \quad k=1,2,3,4 .
\end{gathered}
$$

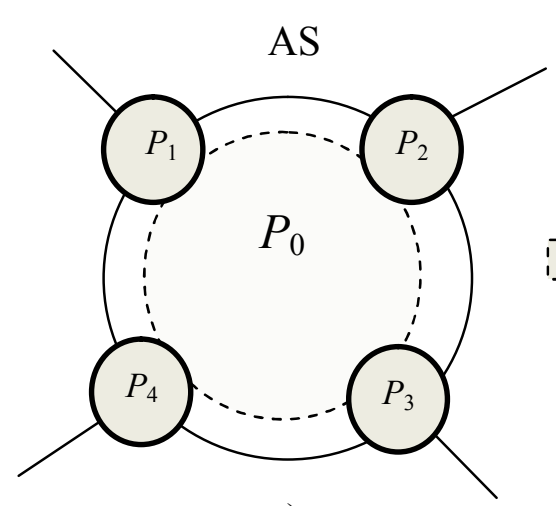

a)

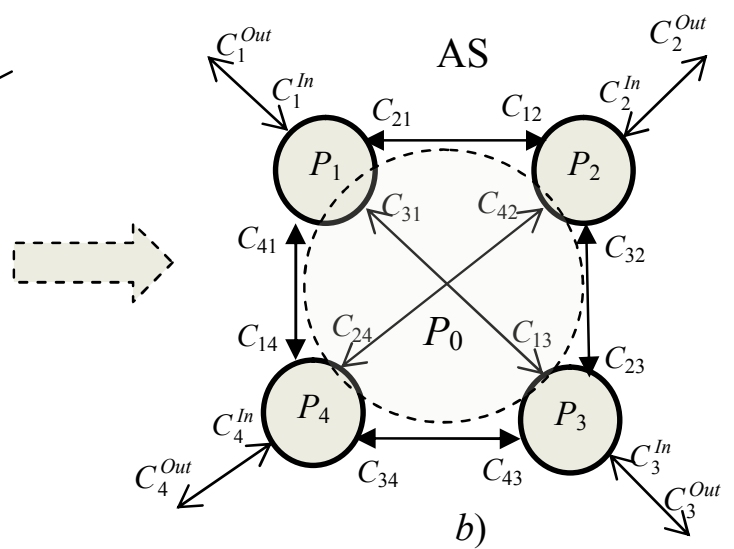

c)

\begin{tabular}{|c|c|c|c|c|c|c|}
\hline$C$ & Ext & $\begin{array}{c}P_{0} \\
(\mathrm{AS})\end{array}$ & $P_{1}$ & $P_{2}$ & $P_{3}$ & $P_{4}$ \\
\hline Ext & & $C_{0}^{\text {In }}$ & $C_{1}^{\text {Out }}$ & $C_{2}^{\text {Out }}$ & $C_{3}^{\text {Out }}$ & $C_{4}^{\text {Out }}$ \\
\hline$P_{0}(\mathrm{AS})$ & $C_{0}^{\text {Out }}$ & $\sum$ & $C_{01}$ & $C_{02}$ & $C_{03}$ & $C_{04}$ \\
\hline$P_{1}$ & $C_{1}^{\text {In }}$ & $C_{10}$ & $C_{11}$ & $C_{12}$ & $C_{13}$ & $C_{14}$ \\
\hline$P_{2}$ & $C_{2}^{\text {In }}$ & $C_{20}$ & $C_{21}$ & $C_{22}$ & $C_{23}$ & $C_{24}$ \\
\hline$P_{3}$ & $C_{3}^{\text {In }}$ & $C_{30}$ & $C_{31}$ & $C_{32}$ & $C_{33}$ & $C_{34}$ \\
\hline$P_{4}$ & $C_{4}^{\text {In }}$ & $C_{40}$ & $C_{41}$ & $C_{42}$ & $C_{43}$ & $C_{44}$ \\
\hline
\end{tabular}

Fig. 1. Virtualization of the connected network topology:

a) Physical network topology graph; b) Virtualized mesh network topology graph;

c) Virtualized weighted directed network graph 
Each element $c_{k m} \in C_{A S}^{\text {Transit }}(k, m)$ of matrix $C_{A S}^{\text {Transit }}$ we leverage as a virtual simplex channel (VSC) $\theta_{k m}$ wherein the following axioms are valid.

Axiom 1: Any couple of AS ports is equipped with two directed virtual simplex channels which form an asymmetric or symmetric duplex virtual channel; any virtual simplex channel has predefined virtual throughput and regular time delay of transit packet through AS.

Axiom 2: Any virtual simplex channel is performed on the data link layer due to periodic circulation of "conveyor transporting modules" (CTM) with fixed frequency; the module payload of CTM is instantly variable from maximal possible value to zero (default CTM); the virtual channel throughput is defined by maximal CTM payload and CTM circulation frequency.

Axiom 3: The optional characteristics of any virtual simplex channel (time delay, circulation frequency and virtual throughput) are smooth functions of the current time and therefore, can be taken as stationary parameters within the local time interval.

To clarify given axioms we consider the following reasoning. One of the possible ways to construct a conveyor transporting module CTM is utilizing the standard Ethernet frame with maximal payload of 1500 bytes. In 1 Gbps physical channel the maximal frequency of CTM circulation is of about 80 $\mathrm{KHz}$. This axiomatic basis defines a cross-layer system architecture that unifies L2 and L3 OSI layers.

QoS-based resource scheduling in packet channel. Based on aforesaid axioms we define multimedia queuing function (MQF) that embodies the L2/L3 cross-layered system interaction while processing two types of queues to be multiplexed in a channel: a) real time queues (RTQ) for virtual end-toend connection; $b$ ) packet data queues (PDQ) which are tolerant to the overall time delay (fig. 2). RTQ and PDQ queues can get performance due to integrated network device of extended functionality, which combines properties of TDM, switching and packet routing [15].

The multimedia queuing function MQF operates with the so called RTQtable shown in fig. 2, a. This table indicates that real time queue number 1 (RTQ-1) leverages segments of 8 unit size (i.e. 8 octets) which are to be inserted into the conveyor transporting modules with the frequency $f / \lambda=f / 2$ (e.g. any second CTM module must have reserved slot to allocate the real time segment RTQ-1 of 8-units along with the multiplexing overhead. Similarly, any fourth CTM module must have a reserved slot for RTQ-2 of 10 units along with overhead needed. In case the module payload MPL is 100 units, two virtual connections (RTQ-1, RTQ-2) along with one packet data queue (PDQ-1) established and 1 unit overhead, we obtain the diagram of channel scheduling shown in fig. $2, b$. 
All the odd CTM modules in fig. $2, b$ are available to allocate 100 units information from the packet data queue PDQ-1; any fourth CTM contains two real time segments $(8+1=9$ units from RTQ- 1 and $10+1=11$ units from RTQ-2) and therefore, $100-(9+11)=80$ units are available for packet data queue allocation; any other CTM module (e.g. number 2, 6, 10, 14, ..) give $100-9=91$ units free for PDQ data. In our case, the scheduling diagram is periodic with 4 CTM cycling. In general case, the cycling period is calculated as least common multiple for all the frequency dividing factors in RTQ table.

To guaranty that none of RTQ segment be pending for service more than CTM circulation period, the following condition must be satisfied:

$$
\sum_{n} s_{n}<M P L_{\max }-\text { Overhead, }
$$

where $s_{n}$ is the size of real time segment arrived to the RTQ-n queue; $M P L_{\max }$ is maximal size of conveyor transporting module CTM; Overhead is the overall overhead of the multimedia data encapsulation (including all the real time and packed data segments). The condition (4) must be verified for any couple of nodes within the transporting path.

Now, for any two ports of an autonomous transporting network (or subnetwork) the local time delay for real time data is limited through the following relation: $\Delta T_{n}<\Delta t_{n}+\theta_{n}=\frac{\lambda_{n}}{f}+\theta_{n}$, where $\theta_{n}$ is the regular time delay of data transmission with respect to data flow associated with real time queue RTQ-n in fig. 2. For instance, if diameter of transporting network does not exceed $200 \mathrm{Km}$, the CTM circulation frequency is $f=80 \mathrm{KHz}$ and frequency factor is $\lambda=80$, then $\Delta T_{n}<2 m s$.

Conclusion. The end-to-end resource reservation for the QoS-aware real time packet data transmission is a complex problem arising at the edge of autonomous systems. Eventually, neither IP-based resource reservation protocols nor SDN solutions demonstrate promising achievements in reliable voice/video communication over the Internet which can be actually competitive to circuit switched TDM domain performance. Analysis testifies that decisive step ahead is needed to advance open system interconnection model and protocols for extended IMS evolution. 


\begin{tabular}{|c|c|c|c|c|}
\hline \multirow{2}{*}{$\begin{array}{l}\text { Real time } \\
\text { queues }\end{array}$} & \multicolumn{3}{|c|}{ Real Time Queuing Table } & \multirow{3}{*}{$\begin{array}{c}\text { Packet } \\
\text { data } \\
\text { queues }\end{array}$} \\
\hline & $\begin{array}{c}\text { Queue } \\
\text { number } n\end{array}$ & $\begin{array}{l}\text { Segment } \\
\text { size } S\end{array}$ & $\begin{array}{l}\text { Frequency } \\
\text { factor } \lambda\end{array}$ & \\
\hline$R T Q-1$ & 1 & 8 & 2 & \\
\hline \multirow[t]{2}{*}{$R T Q-2$} & 2 & 10 & 4 & $P D O-1$ \\
\hline & $\ldots$ & $\ldots$ & $\ldots$ & $\frac{P D Q^{-1}}{P D Q-2}$ \\
\hline$R T Q-n$ & $n$ & $S_{n}$ & $\lambda_{n}$ & \\
\hline
\end{tabular}

\begin{tabular}{|c|c|c|c|c|c|c|c|c|c|c|c|c|c|}
\hline $\begin{array}{c}\text { CTM } \\
\text { Number }\end{array}$ & 1 & 2 & 3 & 4 & 5 & 6 & 7 & 8 & 9 & 10 & 11 & 12 & 13 \\
\hline RTQ-1 & & 9 & & 9 & & 9 & & 9 & & 9 & & 9 & \\
\hline RTQ-2 & & & & 11 & & & & 11 & & & & 11 & \\
\hline PDQ-1 & 100 & 91 & 100 & 80 & 100 & 91 & 100 & 80 & 100 & 91 & 100 & 80 & 100 \\
\hline
\end{tabular}

Fig. 2. The multimedia queuing function MQF

In this work, an axiomatic basis for enhanced packet based internetworking design is formulated to combine QoS-aware synchronous time division multiplexing and asynchronous packet-switching with statistical multiplexing technique. An appropriate cross-layer method originated to leverage integrated heterogeneous data flow in a converged digital channel based on cyclic conveyor module resource scheduling. Proposed method facilitates QoS-fair queuing performance and real time data latency control in a packet channel.

\section{References:}

1. Srikanth, Jagabathula and Shah, D. (2010), "Fair Scheduling in Networks through Packet Election", available at: http://arxiv.org/pdf/0808.2530.pdf.

2. RFC 2205 (1997), "Resource reservation protocol (RSVP) - version 1 functional specification", available at: https://tools.ietf.org/html/rfc2205.

3. RFC 4094 (2005), "Analysis of existing Quality of Service signaling protocols", available at: https://tools.ietf.org/html/rfc4094.

4. Erkka Honkavaara (2008), "Cost of deploying new technologies", available at: www.cse.hut.fi/en/publications/B/1/papers/Honkavaara_final.pdf.

5. Rifai, M., Lopez-Pacheco, D. and Urvoy-Keller, G. (2015), "Coarse-grained Scheduling with Software-Defined Networking Switches", available at: http://conferences.sigcomm.org/sigcomm/2015/pdf/papers/p95.pdf.

6. Cox, C. (2014), "An introduction to LTE, LTE-advanced, SAE, VoLTE and 4G mobile communications, second edition", John Wiley \& Sons, Ltd., 449 p.

7. "IP-Multimedia Subsystem", available at: www.3gpp.org/technologies/keywordsacronyms/109-ims.

8. Cisco Systems, Inc. (2003), Internetworking Technologies Handbook, 4-th Editio, Cisco Press, $1128 \mathrm{p}$.

9. Tanenbaum, A.S. and Wetherall, D.J. (2011), Computer Networks, 5-th Edition, Prentice Hall PTR, 938 p.

10. "The Evolution of IMS", available at: www1.huawei.com/enapp/198/hw-078982.htm. 
11. Ericsson (2008), "MMTel - a standard for multimedia services over IMS", available at: www.3glteinfo.com/wp-content/uploads/2013/10/mmtel-multimedia-services-110417144651phpapp02.pdf.

12. Tsagkaropoulos, M. (2007), "IMS Evolution and IMS Test-Bed Service Platforms", IEEE 18th International Symposium on Personal, Indoor and Mobile Radio Communications, 3-7 Sept. 2007, Athens, Greece, pp. 1-6.

13. Marek, Sue (2016), "Verizon, AT\&T miss initial VoLTE interoperability target, promise it will happen this year", available at: www.fiercewireless.com/story/verizon-att-miss-initialvolte-interoperability-target-promise-it-will-happ/2016-02-29.

14. Hardawar, D. (2014), "Verizon closes $\$ 130 \mathrm{~B}$ deal to buy out Vodafone's stake in Verizon Wireless today", available at: http://venturebeat.com/2014/02/21/verizon-closes-130b-deal-tobuy-out-vodafones-stake-in-verizon-wireless-today/.

15. Dohler, M. (2012), "LTE-A PHY Layer Overview \& Femto Design Challenges", available at: www.youtube.com/watch? $\mathrm{v}=\mathrm{JyKJ} 4 \_$CybiE.

Received 16.05.2016

The article is presented by doctor of technical sciences, director of the Institute of Radio, Television and Information Security of "O.S. Popov ONAT" Vasiliu E.V.

Tikhonov Victor, Dr. Tech. Sci., Professor

Odessa National Academy of telecommunications

Str. Kovalska, 1, Odessa Ukraine, 65029

Tel.: 067-752-13-90, e-mail: victor.tykhonov@onat.edu.ua

Taher Abdullah, PhD Student

Odessa National Academy of telecommunications

Str. Kovalska, 1, Odessa Ukraine, 65029

Tel.: 063-788-43-73, e-mail: abidalla_2004@yahoo.com

Tykhonova Olena, Teacher

Odessa National Academy of telecommunications

Str. Kovalska, 1, Odessa Ukraine, 65029

Tel.: 097-490-56-18, e-mail: elena.tykhonova@onat.edu.ua 
УДК 621.391

Конвесрно-модульний розподіл ресурсів телекомунікаційного пакетного каналу / Тіхонов B.I., Тахер А., Тихонова О.В. // Вісник НТУ "ХПІ". Серія: Інформатика та моделювання. - 2016. - №. 21 (1193). - С. 152 161.

Стаття присвячена дослідженню методів резервування i розподілу ресурсів каналу в мережах 3 пакетною комутацією. Сформульовано аксіоматичний базис для вдосконалення протоколів між-мережевої взаємодії. Запропоновано міжрівневий метод обробки гетерогенного потоку даних в цифровому каналі на основі розподілу ресурсів за допомогою циклічних конвеєрних модулів. Іл.: 2. Бібліогр.: 15 назв.

Ключові слова: телекомунікаційний пакетний канал, конвеєрномодульний розподіл ресурсів, циклічні конвеєрні модулі.

\section{УДК 621.391}

Конвеерно-модульное распределение ресурсов телекоммуникационного пакетного канала / Тихонов В.И., Тахер А., Тихонова Е.В. // Вестник НТУ "ХПИ". Серия: Информатика и моделирование. - 2016. - №. 21 (1193). - C. $152-161$.

Статья посвящена исследованию методов резервирования и распределения ресурсов канала в сетях с пакетной коммутацией. Сформулирован аксиоматический базис для усовершенствования протоколов межсетевого взаимодействия. Предложен межуровневый метод обработки гетерогенного потока данных в цифровом канале на основе распределения ресурсов с помощью цикличных конвейерных модулей. Ил.: 2. Библиогр.: 15 назв.

Ключевые слова: телекоммуникационный пакетный канал, конвейерномодульное распределение ресурсов, цикличные конвейерные модули.

UDC 621.391

Conveyor module resource scheduling in packet based communication channel / Tikhonov V.I., Taher A., Tykhonova O.V. // Herald of the National Technical University "KhPI". Subject issue: Information Science and Modeling. 2016. - №. 21 (1193). - P. 152 - 161.

The paper focuses researches on channel resource reservation and scheduling in packet based networks. An axiomatic basis for enhanced packet based internetworking design formulated. A cross-layer method originated to leverage integrated heterogeneous data flow in converged digital channel based on cyclic conveyor module resource scheduling. Figs.: 2. Refs.: 15 titles.

Keywords: communication channel, conveyor module resource scheduling, cyclic conveyor module. 